\title{
Dust Impact Monitor DIM onboard Rosetta/Philae: Comparison of experimental results and the theory behind the instrument
}

Harald Krüger $^{1}$, Walter Arnold ${ }^{2,3}$, Hans-Herbert Fischer ${ }^{4}$, Alberto Flandes ${ }^{5}$, Attila Hirn ${ }^{6}$, Alexander Loose ${ }^{1}$, Klaus Seidensticker ${ }^{7}$, Matthias Sperl ${ }^{8}$

(1) MPI für Sonnensystemforschung, Katlenburg-Lindau, Germany; (2) Department of Materials, Saarland University, Saarbrücken, Germany; (3) 1. Phys. Institut, University of Göttingen, Germany; (4) DLR, Space Operations, MUSC, Köln, Germany; (5) Ciencias Espaciales, Instituto de Geofísica, UNAM, México; (6) MTA Centre for Energy Research, Budapest, Hungary; (7) DLR, Institute for Planetary Research, Berlin, Germany; (8) DLR, Institut für Materialphysik im Weltraum, Köln, Germany

\section{Abstract}

The Rosetta lander spacecraft Philae will land on the nucleus surface of comet 67P/ChuryumovGerasimenko in November 2014. Philae is equipped with the Dust Impact Monitor (DIM). DIM is part of the SESAME instrument package onboard Philae [Seidensticker et al., 2007] and employs piezoelectric PZT sensors to detect dust particle impacts. The sensors are mounted on the outer side of a cube, facing in orthogonal directions, this way allowing for the detection of grains approaching normal to the nucleus surface and from two horizontal directions. DIM's total sensitive area is approximately $70 \mathrm{~cm}^{2}$. It will measure impacts of sub-millimeter and millimeter sized ice and dust particles that are emitted from the nucleus and transported into the cometary coma by the escaping gas flow. A grain-size dependent fraction of the emitted grains is expected to fall back to the nucleus surface due to gravity. DIM will be able to detect both these components, the backfalling particles as well as the grains hitting the detector on direct trajectories from the surface. With DIM we will be able to measure fluxes, impact directions as well as the speed and size of the impacting cometary particles.

We studied the performance of DIM based on impact experiments and compare the measurements with the sensor's expected theoretical behaviour as derived from Hertz' theory of elastic impact. We simulated impacts onto the DIM sensor with spherical particles of different materials (steel, glass, ruby, polyethylene), particle radii between 0.2 and $0.5 \mathrm{~mm}$ and impact speeds up to $2 \mathrm{~m} \mathrm{~s}^{-1}$ [Flandes et al., 2013]. Cometary grains on ballistic trajectories will have impact speeds below the escape speed from the nucleus surface (approximately $1.5 \mathrm{~ms}^{-1}$ ), thus the impact speeds achievable by our experiments cover the range expected at the comet. Our results show that the signal strength and the contact times measured with the DIM PZT sensors can be well approximated by Hertz' contact mechanics.

\section{References}

[Flandes et al., 2013] Flandes, A., Krüger, H., Loose, A., Sperl, M., Seidensticker, K. J., Fischer, H.H., and Arnold, W. (2013). Dust Impact Monitor (DIM) onboard Rosetta/Philae: Comparison of experimental results and the theory behind the experiment. Planetary and Space Science. submitted.

[Seidensticker et al., 2007] Seidensticker, K. J., Möhlmann, D., Apáthy, I., Schmidt, W., Thiel, K., Arnold, W., Fischer, H.-H., Kretschmer, M., Madlener, D., Péter, A., Trautner, R., and Schieke, S. (2007). Sesame - An Experiment of the Rosetta Lander Philae: Objectives and General Design. Space Science Reviews, 128:301-337. 